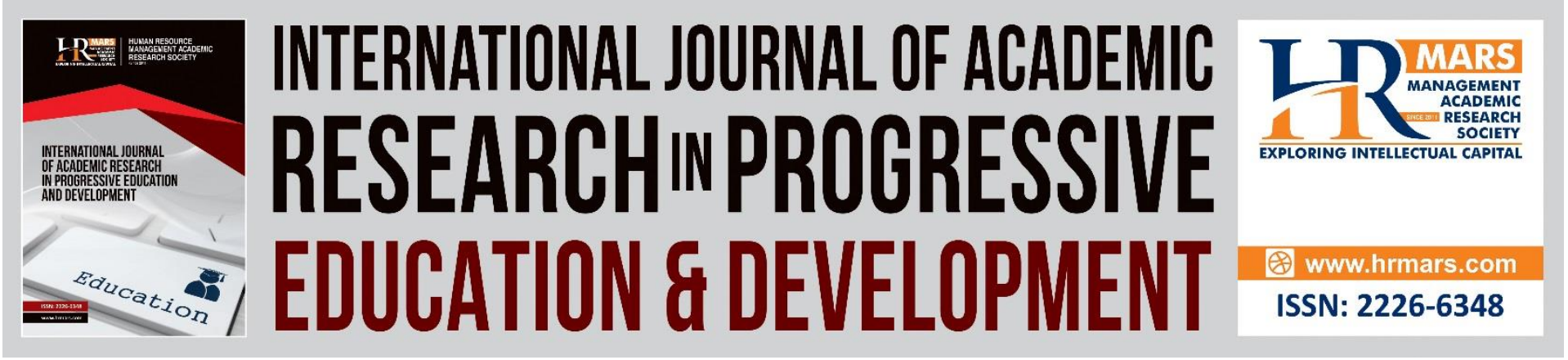

\title{
Attention, Perception, Memory, and Creativity: Understanding the Impact of Culture and Their Diversity in Cognitive Processes
}

Saeid Motevalli, Mohd Sahandri Ghani Hamzah, Mina Tresa Anak Michael

To Link this Article: http://dx.doi.org/10.6007/IJARPED/v10-i3/11006

DOI:10.6007/IJARPED/v10-i3/11006

Received: 04 July 2021, Revised: 09 August 2021, Accepted: 24 August 2021

Published Online: 23 September 2021

In-Text Citation: (Motevalli et al., 2021)

To Cite this Article: Motevalli, S., Hamzah, M. S. G., \& Michael, M. T. A. (2021). Attention, Perception, Memory, and Creativity: Understanding the Impact of Culture and Their Diversity in Cognitive Processes.

International Journal of Acdemic Research in Progressive Education and Development, 10(3), 975-992.

Copyright: (C) 2021 The Author(s)

Published by Human Resource Management Academic Research Society (www.hrmars.com)

This article is published under the Creative Commons Attribution (CC BY 4.0) license. Anyone may reproduce, distribute, translate and create derivative works of this article (for both commercial and non-commercial purposes), subject to full attribution to the original publication and authors. The full terms of this license may be seen

at: http://creativecommons.org/licences/by/4.0/legalcode

Vol. 10(3) 2021, Pg. 975 - 992

http://hrmars.com/index.php/pages/detail/IJARPED

JOURNAL HOMEPAGE

Full Terms \& Conditions of access and use can be found at http://hrmars.com/index.php/pages/detail/publication-ethics 


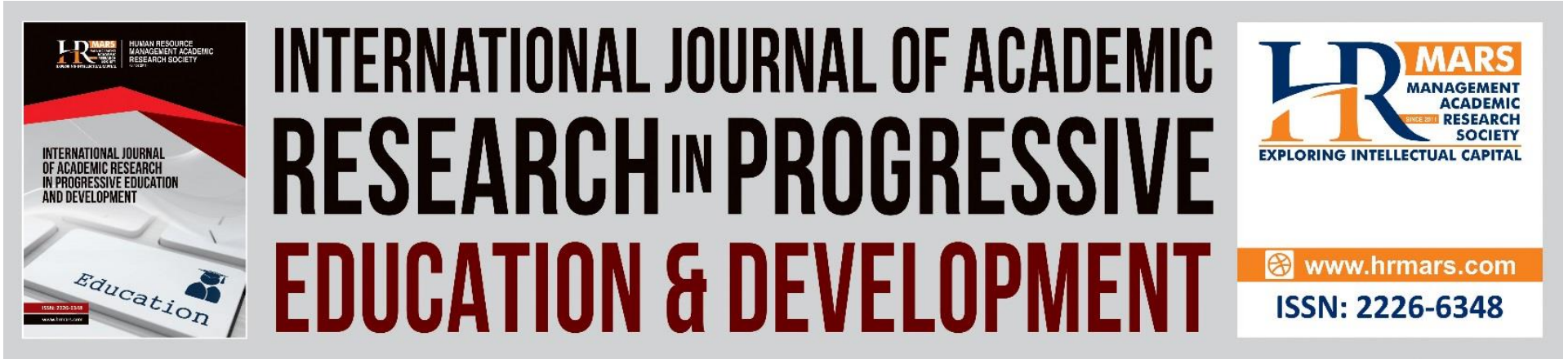

\title{
Attention, Perception, Memory, and Creativity: Understanding the Impact of Culture and Their Diversity in Cognitive Processes
}

\author{
Saeid Motevalli \\ PhD, Universiti Putra Malaysia, Serdang, 43400, Selangor, Malaysia \\ Email: motevalli.saeid@gmail.com \\ Mohd Sahandri Ghani Hamzah \\ PhD, Kolej Universiti Poly-Tech MARA, Cheras,56100, Kuala Lumpur, Malaysia \\ Email: sahandri@kuptm.edu.my
}

\begin{abstract}
Mina Tresa Anak Michael
Department of Psychology and Counselling, Faculty of Human Development, Universiti Pendidikan Sultan Idris, Tanjong Malim, Malaysia

Email: minatresa@gmail.com
\end{abstract}

\begin{abstract}
The purpose of the review article is to deepen the understanding of cultural diversity in terms of cognitive processes to avoid cultural conflicts such as misunderstanding and miscommunication. In this review, we found that there is a link that connected some cognitive processes with culture from various perspectives in our recent findings. The overall research findings suggested that there are pieces of evidence of how culture can play a role and differ from other cultures in cognitive processes such as perception, attention, memory, and creativity. Evaluation and the measurement of the culture and cognition by the researchers in the studies were included in this review together with the results of the findings and some future implications for further research proposed by the researchers of the study in some studies reviewed. We will also review how people of various cultures adapt their cognition which differs them from other cultures in some studies. In conclusion, we hope that more factors should be considered for cross-cultural studies in cognition, and further critical interpretation is needed in this review article to made people realize the diversity of cognition in culture and accept it.
\end{abstract}

Keywords: Cross-cultural, Cognitive Process, Attention, Perception, Memory, Creativity

Introduction

According to Fernandez (2010), he defined culture as "the integrated pattern of human knowledge, belief, and behavior that depends upon the capacity for learning and transmitting 
knowledge to succeeding generations" (Fernandez, 2010 as cited in Boyle, Wongsri, Bahr, Macayan, \& Bentler, 2020). There have been many conflicts such as miscommunication and misunderstanding that can occur due to the lack of understanding or unwillingness to understand cultural diversity in the cognitive process. Many should view cultural diversity and cognition as something that is related. This is because an individual's psychological well-being, goal orientation, motivation, and study approach might have been impacted by group members which shared the same configuration of thoughts, feelings, and behaviors (Gong \& Fan, 2006; Hsin \& Xie, 2014; Manikutty, Anuradha \& Hansen, 2007 as cited in Boyle et al., 2020). There has been a long history of how psychologists view culture and cognition for example in individual differences in personality, motivation, and cognition according to Saklofske \& Eysenck (2004) and how it is "influenced by social learning in adapting to cultural environments" (Saklofske \& Eysenck, 2004; Chang et al., 2011; Chiu et al., 2008; Chiu, Chia \& Wan, 2015; Stankov \& Lee, 2008; van de Vijver \& van Hemert, 2008 as cited in Boyle et al., 2020). Therefore, the methodology that we used in collecting the findings is by using an electronic database such as Google Scholar, Frontiers, PubMed, and Springer. We collected the recent findings dated from 2017 to 2020 to see the current knowledge of cognition and cultures.

In reality, there are many domains of cognition that are influenced by culture. Humans in different cultures have adopted different cognitive views to adapt themselves in the culture such as norms, values, and beliefs which are the products of the cognitive process. According to Hofstede (1980) in Jang et al. (2019), among the 53 countries studied, the United States was considered the most individualistic country while South Korea was considered a highly collectivist country. As one of the collectivist countries that emphasize the community, South Korea reflects a holistic thinking style when communicating while Western countries such as the United States reflect more on analytic thinking style as they use more direct and noncontextual communications (Francesco et al., 2005; Hall, 1976 as cited in Jang et al., 2019). Holistic thinkers often connect objects and perceive the existence of causal influence for subsequent events for the object while analytic thinkers are more independent and detached when viewing or explaining an object which is more prevalent in Western cultures (Jang et al., 2019). There have been previous researches on these two thinking styles in the cross-cultural study. For example, in early research about attention, Masuda \& Nisbett (2001) synthesized that the differences between the thinking of Western countries representatives such as Americans as the participants and Eastern countries such as Japanese as their participants in their study showed that "US-Americans tended to report a focal fish swimming in an aquarium, while Japanese participants reported more details from the background, including plants and smaller animals when describing a picture. Similar differences were found in visual attention processes as measured by participants' gaze behavior" (Masuda et al., 2001 as cited in Köster et al., 2018). Due to differences in culture such as individualistic and collectivist culture as well as their thinking styles processes in Western countries with Eastern countries, it is possible to understand why conflict occurs among people of the different cultural contexts in terms of the cognitive processes such as attention and perception.

There is also a distinction in defining cognitive processes such as attention where it has a limited capacity in consciousness toward certain stimuli while in perception, the interpretation of stimuli or sensation was often referred to. While they may be different in terms of references, it appears that they might be universal or different across cultures. 
Therefore, in this review article, we carefully classified and analyzed critically the previous findings to deepen the understanding of the relationship between culture and cognition as well as how they differ from other cultures in nurturing an individual's cognitive processes and adapting it in their cultures such as attention, perception, memory, and creativity. We included how the researchers evaluate their empirical findings as well as their limitations in some studies demonstrated and their proposed future directions for further researches in their findings. Finally, we concluded the review article with discussions and our conclusion for future studies.

\section{Attention}

Despite our senses, one may not necessarily have the same view in terms of attention and perception. Universally, we may have sensory receptors to sense stimuli for attention and perception but every individual has their own mental representation especially about their culture. Numerous studies can be used to study whether culture was preexisted in influencing one of the domains of cognition such as attention and differ from one another in each culture.

\section{Holistic Thinking Style and Analytic Thinking Style in Attention}

One of the studies conducted by Jang \& Shin (2019) demonstrated the cultural differences in advertisement attentions between Korean consumers and the United States consumers. In this present study, the experiment about attention between different consumers was tested where the participants were recruited from distinct cultures which are from South Koreans and the United States respectively for three experimental types of research. Consistent with the previous findings by Masuda et al (2001), the researchers reported that one of the results shows that Korean consumers respond more favorably to the products when an ingredient is presented first and the final product is shown later in the advertisement while Americans responded more favorably when the order is reversed across three experimental pieces of research (Jang et al., 2019). The researcher concluded that the content order of the advertisement is important too when in different cultures and reflect how Koreans tend to emphasize and connected more meaningful communications which are consistent with the study proposed by Hofstede in 1980 which were related to the thinking styles (Jang et al., 2019). They also synthesized that cultures such as Americans used analytical thinking styles tend to weigh more on initial information while Eastern cultures such as Japanese that use holistic thinking styles are more prone to subsequent information (Noguchi, Kamada, and Shrira, 2014 as cited in Jang et al., 2019).

\section{Context-Sensitive Attention}

This is supported by another piece of evidence in one of the studies that measure the variety of attention in a variety of tasks where Köster et al. (2018) reported that children from urban Japan and urban Germany show higher context-sensitive attention in some tasks. The samples taken in their study were taken from different cultural contexts such as urban Japan, urban Germany, and rural Cameroon. Their results also shown that for levels of parallel attention and learning from others' activities, Cameroonian children scored lower compared to the urban samples (Köster et al., 2018). In this study, optical illusion tasks such as Ebbinghaus illusions, Müller-Lyer illusion, Sander illusion, in picture descriptions, and eye-tracking paradigm were used to assess the visual attention together with parallel action task and a rule-based game that was also used to assessed attention to and learning process from others 
activities. The results were mixed but after being taken together, they concluded that human basic cognitive processes vary from different cultures and suggest that cultural context has influenced on focal or contextual elements of an object. However, they also noted that the findings do not yet have a consistent construct that aligns visual attention across different types of tasks (e.g., verbal, non-verbal, semantic, abstract) for early childhood years and has the potential to express more about the cultural-specific context differences for visual attention in later development (Köster et al., 2018).

\section{Visual Spatial Attention and Gaze}

The influences of culture and cultural differences in visual-spatial attention between Western countries and Eastern countries investigated by Jang and his colleague study was further researched in another study by Takao, Yamani \& Ariga (2018) that demonstrated the gazecueing effect between the United States and Japanese participants which are related to cognitive attention. The human gaze is important for us to focus and visual attention was used to select the stimuli we wanted to focus on and ignore the others. The Gaze-cueing effect according to Takao et al. (2018) was referred to as 'the direction of gaze automatically and exogenously guides visual-spatial attention' (Takao et al., 2018). Takao and his colleague found that there is a difference in the gaze-cueing effect in the study demonstrated when the American participants showed a longer gaze-cueing effect at long stimulus onset asynchrony (SOA) while Japanese participants showed no gaze-cueing effect for long SOA. The researchers explained that the differences in the gaze-cueing effect are probably because the East Asians were better in detecting changes at periphery visual while the Westerners were better in detecting changes in the center of the visual field (Bonduroglu, Shah \& Nisbett, 2009 as cited in Takao et al., 2018). In sum, they concluded that there are pieces of evidence of cultural differences for cognitive process in attention.

\section{Attention Focus in Distraction}

Another study founded also further implied the evidence of cultural differences and their role in attention which supports the evidence shown by other researchers that were reviewed before about cognitive attention.

In this study demonstrated by Amer, Ngo, and Hasher (2017), they aimed to investigate the differences between East Asians and Western undergraduate students as their participants in terms of attention and implicit memory. However, we will only focused on reviewing how the attention of participants from different cultures differs. The participants were asked to ignore the distraction given by the researchers while completing the task which was named as Stroop Task in Experiment and 1 back task on pictures in Experiment 2 (Amer et al., 2017). The findings were evaluated and East Asian participants were founded to use the broader focus of attention which was used in East Asian cultures when completing the task even when it is considered detrimental to the task performance compared to Western participants which were less inclined to that tendency. These significant differences in attention between these two cultures have provided pieces of evidence that culture is an important factor to be considered and it can influence the attention of the participants when completing their target task. (Amer et al., 2017).

In summary, the behavioral shreds of evidence and evaluation results shown by the participants in these studies suggest that culture and their differences in thinking can be contributed to cognitive attention which in turn can influence their cognitive process. More 
robust implications and further pieces of evidence from research findings were needed to explain more about the discrepancies of the cultural differences and attention to deepen our understanding of cultural diversity in cognition.

\section{Perception}

In this section, more study and findings will be used to discuss another cognitive process which is the human perception from a different culture. We decided to include various types of perception ranging from spatial, visual, tonality, taste, and smell perception to understand whether the differences exist in each culture. Without further delay, we will now discuss the first spatial perception.

\section{Spatial Perception}

In 2017, Saulton, Bülthoff, De La Rosa, \& Dodds decided to shed some light on how cultural differences influence people's room size perception by demonstrating the differences of spatial perception between two different cultures from Germans and South Koreans. In this study, the total participants were 72 university students which contained thirty-six students from Tübingen University, Germany, and thirty -six university students from Seoul Korea University. A psychophysical task is used in which participants had to judge whether a rectangular room was smaller or larger than a square room of reference. The rectangularity of the room was varied by the researchers from which the room is viewed (Saulton et al., 2017). The results showed that the South Koreans were less biased compared to Germans in terms of room judgments of virtual rooms' rectangularity and viewpoint. They noted that this is probably because the Koreans look and observe around more about the room compared to Germans. They synthesized that Koreans might consider a greater volume of information about the room such as the size of the dimensions of the room compared to Germans participants. The researchers also noted that the findings are in line with the previous studies that they synthesized where spatial biases are less susceptible for East Asians that require a judgment of surrounding context compared to Westerners (Saulton et al., 2017). The researchers also proposed that further research between viewing behavior and spatial judgment perception is needed to expand this cross-cultural study. The evidence shown by this study has helped to increase our understanding of spatial perception besides their differences in different cultures.

\section{Visual Perception}

While Jang et al. (2018) study about consumers' cognitive processes such as attention, Wiberg \& Månsson (2019) conducted a study about another cognitive process which is the perception by demonstrating a cross-cultural study between consumers' perceptions from Sweden, India, and Japan in social media advertisement. In this study, participants are required to take part in artificial and recorded Facebook feedback which consisted of advertisements that will be used in the qualitative data for an interview between the participants and the researchers. By referring to Hofstede's dimensions and model, the advertisement gave connected four dimensions in terms of femininity, masculinity, individualism, collectivism, restraint, indulgence, and power distance. Wiberg and his colleague (2019) found that although the qualitative data assessed were highly subjective and individual, they quoted that there was a similarity between the participants' attitudes, brand recognition, shapes colors, compositions, and interests. However, when referring to Hofstede's model for the 
advertisement, it was still debatable whether national culture has influences on consumer's perception in social media advertising as the researchers found only one of Hofstede's dimensions has correlation which is individualism. The researchers suggest further researchers with the larger networks should be used as the findings were found to have cultural discrepancies with social media advertisement perceptions.

It is surprising to know that many studies often use consumers from different cultural contexts as their samples when it comes to investigating cognition such as attention and perception. In addition to Jang et al (2019); Wiberg et al (2019) studies that used consumers as their samples, Ploom, Pentus, Kuusik \& Varblane in 2020 further documented whether the differences of consumer perception in culture exist by using participants from Northeast Asian and Northern European when investigating about the effect of culture in consumer packaging and perception. Methods such as eye-tracking, facial-expression-based emotion to measure, and choice-based analysis were combined and used to evaluate the differences in consumer perception. The results for their findings found that there are differences in attention between participants from different cultures when the eye-tracking and emotion measurements were analyzed. Ploom et al (2020) synthesized the findings by explaining that the differences in eye-tracking that occur might be due to the differences between their reading/ writing method in their culture when first presented with the information of the packaging. While the positive emotions evoked by both participants in their culture in terms of packaging color are different, it is possible to be explained that it is due to their unconscious affective process that associates the meaning of the color with their culture. Similar to Wiberg et al.(2019) study limitations, Ploom and his colleague also further noted that there are still some limitations and in their study such as small sample size, and thus further researches with the bigger and heterogeneous sample are needed in a future study to understand more about the differences in consumer packaging perception from different cultures (Ploom et al., 2020).

\section{Tonality Perception}

Further studies were added to analyze the differences in another type of perception such as tonality perception between cultures and we are going to review one of the recent studies demonstrated by Matsunaga, Yasuda, Johnson-Motoyama, Hartono, Yokosawa \& Abe (2018) about tonality perception between the Japanese, Chinese, Vietnamese, Indonesian listeners that were recruited from University of Hokkaido American listeners from University of Kansas. With no music education or training, participants from these five different cultural groups were asked to rate the degree of melodic completeness of the final tone and feelings such as happiness and sadness of each melody. Matsunaga et al. (2018) reported there is a difference in responses when different music was presented for each different cultural group such as American and Japanese participants response similarly when Western music are presented while Chinese, Vietnamese and Indonesian participants responded differently. However, when Japanese melodies were presented, Japanese participants show tonal schemas response while Americans, Chinese, Vietnamese and Indonesian participants show different responses. This result shows that there are differences in tonal perception even between people from Eastern countries such as Japanese, Chinese, Vietnamese, and Indonesian. It also explained that although there is an advance in Western music globally, tonal perception in each culture still varies from the other. 


\section{Taste Perception}

Besides hearing and sight perception, it was also possible that people in different cultures have different taste perceptions. Different cultures have different food preferences which might affect people's taste perception. However, it has yet to be concluded due to the lack of studies in taste perception. Trachootham, Satoh-Kuriwada, Lam-ubol, Promkam, Chotechuang, Sasano, \& Shoji (2018) published research investigate the relationship between taste perception and spicy preference of participants from two distinct cultures which were Thai culture and Japanese culture. In this study, 168 participants between the age of fifty to ninety years old were recruited to carry out the study. Electrogustometry and calibrated questionnaires were used to measure the taste threshold and spicy preference of the participants respectively. The findings of the research show that there is a significant difference in taste threshold between these two cultures where Trachootham et al. (2018) reported that Thai participants have a higher taste threshold compared to Japanese participants in the study. At the same time, the data findings also suggested that although Thai participants have a stronger preference for spicy food, they have poorer taste sensitivity and perception compared to Japanese participants that prefer milder taste food (Trachootham et al., 2018). Nevertheless, the researchers noted that there is also a limitation to the study such as the questionnaire items and they suggested that objective measurement such as the dietary record of spice consumption should be included for a more accurate understanding of the taste threshold perception and spicy preference in these different cultures. We think that this proposed limitation is good to be considered to avoid the error variance in the study and determine the accurate assessment of culture as a role in the taste perception differences in a different culture in future studies.

\section{Smell Perception}

Next, the universality of smell perception was also questioned for a better understanding of cultural differences in cognition. One of the recent studies by Bertelsen et al (2020) investigate the effect of sweetness intensity and nationality by using the cross-modal effect of vanilla aroma on different sweeteners for sweetness enhancement. In this study, Bertelsen et al (2020) recruited Chinese and Danish consumers as participants and presented them with three different sets of sweeteners to test the effect of vanilla aroma on different types of sweeteners. The results showed that although there is no significant effect among nationalities in either sweet aroma and sweet intensity, the results of the ratings among different cultures changed when vanilla aroma was added to the sweeteners. The Danish consumers reported to rated higher in the perception of sweetness when the vanilla aroma was added compared to Chinese consumers when the vanilla was added.

Bertelsen et al (2020) explained that the differences in the rating might be caused by crosscultural differences in food qualities which caused different innate mechanisms such as sensitivity towards food in sensory perception (Prescott, 1998 as cited in Bertelsen et al., 2020). The explanation was further integrated by Bertelsen and his colleague that their eating habit might also be one of the reasons as Danish consumers consumed more sweet beverages compared to Chinese consumers which caused higher familiarity in sweetness perception among Danish consumers (Bertelsen et al., 2020). They suggested that dietary questionnaire should also be included in future research to identify and differentiate the effects of nationality and culture in consumer's sensitivity towards aroma (Bertelsen et al., 2020) which were quite similar to how Trachootham et al (2018) proposed to investigate other factors to 
avoid error variances. In sum, many types of research that study different types of perception from different sensory stimuli has held the pieces of evidence that different cultures might have an influence on people's perception and the cognitive process about their perception are different from other cultures.

\section{Memory}

Does culture shape memory? Memory across cultures was important to know as different individuals grew up in different environments and cultural contexts. Different individuals from different cultures may have a different understanding of how memory is developed and ways to organize their memory. In this section, we will discuss and highlight how cultural differences and different types of memory can relate to each other and at the same time discover how people other than cultural factors organize their memory to adapt to their environment.

\section{Adaptation of Culture in Memory Performance}

In Jobson, Whittles, Tsecoutanis, Raj, \& Haque (2019) study which demonstrated crosscultural research that was related to different types of memory which were autobiographical memory, we are going to analyze how different people in culture use it. The researchers aimed to investigate the mediating role of self-construal on the relationship between two cultural groups which are Malay and Australian and the characteristics and functional use of autobiographical memory. (Jobson et al., 2019) In this article, Jobson et al.(2019) synthesized that 'Western individualistic cultures tend to provide lengthier, autonomously focused, egocentric memories that are focused on discrete events that occurred at a particular time and place (i.e. specific memories), when compared to those from Asian collectivistic cultures' (Jobson, 2009; Jobson \& O'Kearney, 2006; 2008; Wang, 2008; Wang \& Conway, 2004; Wang, Leichtman, \& Davies, 2000; Ross \& Wang, 2010; and Wang, 2013 as cited in Jobson et al., 2019). However, they also argued that although there was an abundance of cultural studies and memory characteristics, not many studies were done between culture and the use of autobiographical memory. (Alea, Bluck, \& Ali, 2015 in Jobson et al., 2019) In this research, 71 Caucasian Australian and 50 Malay Malaysian participants were recruited and were asked to do an online questionnaire to achieve their aim on autobiographical memory between these two cultures. The online questionnaire included the Self-Defining Memory task, the Thinking About Life Experiences Revised Questionnaire, and the Self Construal Scale for the participants. Findings show that the Australian participants provided longer, more autonomously oriented, specific memories than Malay participants in the study. (Jobson et al., 2019) The researchers also reported that the Malay participants were more often found to use autobiographical memories for self-continuity compared to Australian participants. This finding supports the other findings that the researchers have also synthesized in their articles where Liao, Bluck, Alea, \& Cheng (2016) reported that the Taiwanese groups use more memory compared to Americans to maintain their self-continuity (Liao et al., 2016 as cited in Jobson et al., 2019). This article's findings highlight that due to collectivistic culture, it is evidence that Malay's society in terms of self-continuity was more difficult and effortful compared to individualistic cultures in Australia.

Similarly, it is also possible that another type of memory such as working memory can be influenced by cultural differences. Gregory, Langton, Yoshikawa, \& Jackson (2020) study found that there is a significant difference in the accuracy of the working memory in eye 
gazing for happy and angry faces between Western participants and Japanese participants. By replicating the method from the previous study by Jackson (2018) in their published research, Gregory and his colleague set up a method where participants for both cultures were shown faces with different facial expressions and gaze direction appear on the screen and were asked to encode, matching the face shown earlier with a button press (Jackson, 2018 as cited in Gregory et al., 2020). Japanese participants were shown to Caucasian faces and Japanese faces while Western participants were only shown to Japanese face stimuli. It is found that in this study, Western participants' working memory was better in happy faces with averted eye gazes while Japanese participants' working memory when viewing Caucasian face stimuli was worse for angry faces with averted gaze. However, there was no significant difference in working memory and eye gaze for Japanese participants with Japanese face stimuli. Gregory et al (2020) concluded their findings by suggesting how culture-specific differences in how working memory for expressive faces are influenced by eye gaze direction. They also further engaged that the findings might be in line with the previous research that suggests Japanese individuals perceive that angry faces with averted gazes are seen as less angry compared to direct gazes (Akechi et al, 2013 as cited in Gregory et al., 2020) and might dilute the priority of the face stimuli in their working memory. Another possibility how there are no significant differences in their working memory when the Japanese participants were shown to Japanese face stimuli is also further synthesized by researchers that it is common in their culture to avert gazes when communicating with other Japanese which are different with Western participants that engage more in mutual gazes. The researchers noted that as most of the face stimuli used in the study were male, it is hoped that female faces stimuli should also be added into the study to investigate the effect of gender on the interaction between memory with emotion and gaze (Gregory et al., 2020).

In addition to this section, another finding on memory by Mickley Steinmetz, Sturkie, Rochester, Liu \& Gutchess (2018) hypothesized that culture can also be one of the factors in memory, especially in scene memory. These assumptions were made by the researchers based on the findings between Western and Eastern culture-focused item context (Masuda et al., 2001 as cited in Mickley Steinmetz et al.,2018). Nevertheless, they found that not many studies were found to associate scene memory with scene incongruity and emotional processing which might attribute to cross-cultural differences and scene memory. 40 East Asians and 41 American participants were recruited in this study and hierarchical linear modeling (HLM) was used to examine the scene memory while controlling for the congruity of the scene and the perceived emotional intensity of the images shown by the participants. Findings by Mickley Steinmetz et al. (2018) show that American participants have better items and background memory compared to East Asian participants even when the congruency and the emotional intensity of the image were controlled. These findings were in line with previous findings (Ji, Peng \& Nisbett, 2000; Masuda, Gonzalez \& Nisbett, 2008; Motevalli et al., 2013; Stanley, Zhang, Fung, \& Isaacowitz, 2013 as cited in Mickley Steinmetz et al., 2018) where East Asians were more distracted with background contextual information. However, Mickley Steinmetz et al. (2018) also found that there was a lack of relative evidence in differences across cultures in memory with emotion and the perception of scene incongruity. Similar to other previous studies by Trachootham et al. (2018) in perception that proposed items as their limitations, Mickley Steinmetz and his colleague also suggest that extending the incongruity of the items or situations might help to provide more understanding and shreds 
of evidence to compare the process of memory in different cultures (Mickley Steinmetz et al., 2018).

\section{Aging and Environment as Other Factors in Memory Performances Across Culture}

After multiple findings, we also come across another possible question whether cognition in memory is different especially when universal cognitive memory error such as aging occurs across all people in the world. Although the studies about memory reviewed hold pieces of evidence that people's memory is influenced by their culture and how they differ from each other in-memory performance, it is also arguable that cognitive memory can be influenced by other factors such as age. In the next studies, we are going to review how other studies conclude their findings of memory with people from different cultural contexts where culture is not a significant factor in the memory performance.

In Gutchess \& Boduroglu (2019) study, we are going to review how people from different cultures commit their cognitive memory errors. 39 young and older adults American were recruited near Brandeis University, while 39 young and 20 older adults Turks were recruited near Boğaziçi Üniversitesi as participants. Responses such as correct responses and error responses such as categorical and semantic errors were recorded by the researchers to examine the memory results between two cultures. The findings show that Americans tend to commit more categorical memory errors for both young and older participants although older Americans commit more error responses and exhibit more false memory than young participants compared to the young and older Turkish participants (Gutchess \& Boduroglu, 2018). This finding was in line with previous findings by Schwartz, Boduroglu, and Gutchess (2014) that suggest memory errors for categorical information were more committed by American younger adults than Turks than blend in both East and West as their culture (as cited in Guthchess et al., 2018). The researchers also suggested that aging also contributes to the tendency in memory error as it is characterized in both Western and Eastern culture that not only increase in memory errors occurs in categorical information, it also occurs in semantically information as age heightened (Carmichael \& Gutchess, 2016 as cited in Guthchess et al., 2018). This study raises one question: as aging is inevitable, is it possible that we can learn from how different cultures reduced cognitive memory errors? Unfortunately, the researchers concluded that there was no evidence to how universal cognitive memory error factors such as aging can be reduced between two cultures although American participants tend to exhibit greater vulnerability in memory errors compared to Turkish participants among older adults in the study.

In addition to Gutchess et al (2018) study that found no evidence of how cognitive memory error can be reduced in different cultures, the study by Sabiniewicz et al (2020) found that the main role for people's memory performance is because of their age and not culture. By recruiting two different populations with traditional versus contemporary populations (Dani of Papua and Polish participants) that lived in a different environment, Sabiniewicz et al. (2020) study aimed to investigate whether the environment affects short-term memory (STM) and long-term memory (LTM). A short story based on everyday activities was used to test the LTM of the participants while a version of the Wechsler Digit Span Forward test (Wechsler, 2008 as cited in Sabiniewicz et al., 2020) by using face parts was used to test the STM of the participants. The changes in the test were done as faces are considered universal all over the world (Sabiniewicz et al., 2020). The results show that Polish participants were better in both task memory especially STM task and concluded that culture is not the significant moderator 
in age-related memory differences for both populations. The researchers explained that the findings for Polish participants were in line with the previous findings by Gleick (1999) where people in industrialized societies used more STM due to the electronic revolution and technical development (as cited in Sabiniewicz et al., 2020). They also concluded that there were no significant differences in age differences for memory performance in both populations and indicated that the memory performance for STM and LTM in both populations might be dependent on environmental conditions which were shown by Polish participants' results (Sabiniewicz et al., 2020). These two findings by Gutchess et al (2018) and Sabiniewicz et al (2020) have provided evidence that cognition such as memory performance may not entirely be influenced by culture but can be by other factors such as age and environment.

\section{Creativity}

In this section, we are going to review the impact of culture on creativity and how it makes creativity from each culture different. Creativity is important as it helps in terms of innovation. It can be observed from history that the Eastern and Western countries have their innovation that might differ from one another. Not only that, the individualistic country such as Western countries might prioritize more on the usefulness of the innovation compared to some collectivist countries in Eastern countries that prioritize more on relatedness with the group in creative innovation. For example, according to Xie \& Paik (2019) review about the cultural differences in creativity and innovation between Asian employees and Western employees, they raised a question among researchers about Asian's belief in their lack of creativity when compared to Western people. Backed with 29 review articles, Xie et al. (2019) noted that some empirical studies that study collectivism, power distance, and uncertainty avoidance proposed by Hofstede's cultural value that characterizes Asian cultures are found to negatively influence creativity and innovation but not all studies are shown so (Xie et al., 2019). This review has evidenced that different cultures might perceive creativity differently. For further understanding, we are going to analyse the relationship between culture and creativity and how the cognitive process of creative work in some cultures.

\section{Creativity's View from Different Cultures}

In Gajda \& Oie (2017) study, they aimed to investigate the creativity profiles between two cultures which were Poland and Japan. The researchers quoted that according to Hofstede (1983), Japan is considered as a collectivist culture which is similar to other Eastern culture such as South Korean (Jang et al., 2019) which emphasize on cooperation, duty and compromise with the group while Poland, one of the Western countries is more dominated by individualistic value (Hofstede, 1983 as cited in Gajda et al., 2017). 597 participants were recruited among students from two universities in Warsaw and two Tokyo universities respectively which consisted of 230 Polish and 364 Japanese participants. The participants were given a questionnaire and asked to answer open-ended questions related to creativity profiles and understanding of creativity. The results show that Polish students indicate independence when presenting creativity while Japanese groups show lower independence in creativity presentation. Gajda et al. (2017) explained that the Japanese function differently compared to European realities as they are more elaborated, depends on the team, and build an effective team as their goal that works well apart from crafting new products (Ahmadi Faqih et al., 2018; Herbig \& Jacobs, 1996 as cited in Gajda, 2017). However, some Japanese 
participants show that rather than making a revolutionary change, they exhibit higher cognitive curiosity, a great interest in acquiring knowledge, and the willingness to learn from traditional skills and customs despite having low creativity ability (Lubart, 1999; Mito, 2015 as cited in Gajda, 2017). In sum, this study represents how two different cultures from two respective countries, Poland and Japan which consist of portrayed individualistic and collectivist values present and perceive their creative mindset. The researchers also suggest that in future research, gender differences should also be included when investigating creativity in cross-cultural studies (Gajda et al., 2017).

In addition to the review, a study by Almer (2020) also provided another evidence for cultural influence in creativity which is quite similar to the study conducted by Gajda and his colleague study on the view of creative profiles in Japanese and Polish participants. Almer's (2020) findings found that both Croatian and Emirates working professionals have significant differences in their views on creativity. By recruiting Croatian and Emirates working professionals that come from different cultures as the participants in the study, the researcher decided to use the survey to analyse the differences of the view in both cultures. It is found that when comes to creativity, Croatian working professionals have a narrower view when considering a product or process as creative with the cues that have been asked to the participants compared to Emirates working professionals that have a broader view on creativity (Almer, 2020). One of the suggestions suggested by the researcher is to conduct more on other countries regardless of their working experience to understand more about the relationship between cultural influence and creativity among working professionals.

Another insight into how different cultures view creativity was also reviewed to understand more about the relationship between culture and creativity view. According to Nemeržitski (2017) study, the researcher found that there is a difference in how different cultures that were examined in the study which were Estonia and Russia participants that vary with individualism and collectivism values respectively differ in their view about creativity. In this study, the researcher noted that Estonian culture was viewed as a society that adapted individualism and collectivist tendencies (Nemeržitski, 2017). Secondary school students from both cultures were recruited and measurements such as open-ended questions, ESTCOL scale, and three components individualism scale were used by the researcher in this study. The result of the study shows that students from Russia defined creativity by identifying creativity more with novel ideas while students from Estonia view creativity more in terms of self-expression and uniqueness. The result also revealed that some students from Estonia show more tendencies towards collectivism while Russian students show high tendencies in collectivism subscales for the nation and at the same time have a high score in individualism subscales for uniqueness and mature responsibility (Nemeržitski, 2017). The researcher suggests further researches should be conducted to learn more about the view of creativity and the learning tendencies of different cultures in collectivism and individualism. It is also possible that the cognitive process of creativity in an individual from a different culture is distinct from one another due to cultural influence.

Next, we will also see how the creative process is perceived from the participants' perspective about the understanding of the creative process from the study conducted by Guess, Tuason, Göltenboth \& Mironova (2018). In this study, Guess and his colleague recruited professional renowned artists as their participants from three different countries with different values and norms such as Germany, the Western-industrialized country; Russia, the former communist country, and Cuba which has a socialist government. The methodology that has been used by 
the researchers to understand more about the cognitive process of each individual is the interview where one part of the questions is asking about the impact of culture on their work. After the qualitative data were analyzed, it is found that there were cross-cultural differences in terms of cognitive, emotional, economic, and societal aspects of the creative process from Cuban, German and Russian participants in this study (Guess et al., 2018). However, we will only review their findings on the cognitive process of creativity from these different cultures. The Russian and German artists were found to prefer concrete when working their creative work while the Cuban artists were found to generally prefer a centrifugal way, being playful and working at different parts with different times when working with art. Guess and his colleague supports the findings by explaining that it is shown by many cross-cultural studies that German participants were often referred to as 'well-oiled machine' (Hofstede, 1997, p. 141; Hofstede, 2001, p. 375 as cited by Guess et al., 2018) in terms of planning compared to other participants from other countries while Russian artist outcome that prefers planning in this findings was due to their holistic view (Guess et al., 2018) which is similar to how the Eastern countries such as South Korean communicate (Jang et al., 2019). While in Cuban participants' results, it is explained that the centrifugal way of Cuban artists in their creative process in this study was following the life approach by Latin American countries that were often described as more flexible and living in the present (Guess et al., 2018).

\section{Task Creativity}

At the same time, we can also see that study by Storme, Lubart, Myszkowski, Cheung, Tong \& Lau (2017) have provided evidence in comparing the differences in culture concerning creativity tasks. The relationship between monocultural and multicultural samples from two different cultures which were from China and France were shown to have different correlations with one another in task creativity. By using electronic version items that measure the psychometric properties of creativity of an individual, it appears that there is a link between the differences of culture in creativity. The results show that Chinese children that live in France have significantly stronger performance in both figural/graphical divergent thinking subtests compared to Chinese children that live in China. In addition, it is also found that both verbal and non-verbal dimensions in one of the electronic version items were shown strongly correlated with samples from a monocultural environment compared to samples from a multicultural environment. Storme and his colleague explained that this outcome result might be due to how bicultural children learn to adapt their behavior according to their cultural context where for example children whose home culture is Chinese but who live in France might show flexible behavior depending on their cultural context (Storme, 2017). However, limitations are inevitable and researchers suggest that language proficiency should also be measured to determine bilingualism in children and their possible effect on task creativity. As the task creativity will be related to multiculturalism and multilingualism, the researchers also suggested that larger samples should also be used for further investigation and a clearer understanding of the impact of culture on task creativity. To be brief, the studies found in culture impact and difference in the cognition process such as creativity view have supported some proof of how creativity is influenced and differs from other cultures.

\section{Discussions}

This review article is composed of research articles that cover attention, perception, memory, and creativity. We found that most of the research articles prefer to compared Western 
countries and Eastern countries in cross-cultural studies. We inferred that the samples selected from both Western countries and Eastern countries are a good comparison to be used in cross-cultural research articles as Hofstede (as cited in Jang et al., 2019) studied that most Western countries such as the United States are more individualistic in cognition while most Eastern countries such as Asian countries like South Korea are highly referred as a collectivist country. In both reviews for attention and perception section, we observed that some researchers (Jang et al., 2019; Wiberg et al., 2019; Ploom et al.,2020 \& Bertelsen et al., 2020) prefer to use consumers other than undergraduate students as their participants in determining the cultural differences in cognition. The selection of This sample was probably done to observe the differences in each culture that adopt different thinking styles or habits when viewing or perceiving a product for example like what has been shown in Jang et al. (2019) findings where South Korean respond more favorably to ingredient first then product in an advertisement. While in-memory section, we also observed that some researchers prefer to research how different culture adapt their culture and the norm of their culture especially cognitive memory for cross-cultural studies. In this way, it increases our knowledge on how cultural differences were adept in an individual's memory in a different cultural context that can help us to avoid misunderstanding or conflict about what is normal in different cultures. Other than that, we also found that the Hofstede model and dimensions such as individualism and collectivism especially because of creativity were often used for cross-cultural studies (Wiberg et al., 2019; Gajda et al., 2017 \& Nemeržitski, 2017). This occurrence in our review articles was in line with Xie et al. (2019) review where most scholars prefer to use collectivism-individualism in their empirical studies due to its relationship with creativity and innovation (Xie et al., 2019). For limitations and future directions proposed by the researchers in some studies, we found that most prefer to expand their network of sample sizes from other cultures in their empirical studies to see more about the discrepancies of cognition across cultures. At the same time, it is also further discussed that some researchers also proposed to add other factors such as gender, habit or the languages spoke for bilingual samples in multiculturalism setting in their empirical studies. This proposed limitation should also be considered to avoid some error variance in their studies as well as to observe the contribution of other factors for cognitive processes in different cultures. In conclusion, we hope that this discussion can help some researchers and scholars to be vigorous and use more alternatives in their studies, and review other dimensions of cognition for better understanding and more acceptance of cultural diversity and their differences in the cognitive thinking process.

\section{Implications and Conclusions}

This review article showed that cognition skills such as attention, perception, memory, and creativity impact significantly culture and cultural identity and lead to shape the way we perceive and understand the world. Besides, the review article has represented some pieces of evidence on how cognitive skills were interrelated with culture and how populations that vary with individualism and collectivism values respectively differ in their view about creativity. We hope that these findings can also assist human science researchers to consider these differences to design prevention and intervention programs for different purposes. It also further discusses other cognitive skills such as attention and perception that can be vital to define our mental and symbolic representations of reality to avoid cultural conflicts such as misunderstanding and miscommunication among society. These findings are applicable for 
researchers and practitioners who work to understand conflicts among people of different cultural contexts in terms of cognitive processes such as attention and perception. This article has denoted the importance of memory across cultures to know different individuals from different cultures may have a different understanding of how memory is developed and ways to organize their memory to adapt to their environment. However, it does not rule out that other factors such as environment or genetic factors were also involved in human cognition. We believed that further advancement was still needed in reviewing the impact of culture in cognition and their differences in diverse cultures and other factors such as genetic factors or environmental factors were still needed to bridge more new findings between cognitive and cross-cultural psychology fields. Last but not least, we were also aware that more critical interpretations were needed in this review article to provide more readings to help people across cultures to deepen their understanding and acceptance in cognition and thinking from other cultures.

\section{References}

Faqih, A. M., Hajebi, Z. M., Monirpour, N., \& Motevalli, S. (2018). The Role of Emotional Intelligence Components Teachers (Composition Class) in Predicting Creativity Aspects of (Writing) of Students. The Journal of Research in Humanities, 25(2), 87-109.

Almer, A. (2020). Cross-Cultural Study on Creativity: How do Croatian working professionals and Emirati working professionals conceptualize creativity?. Retrieved from https://scholarworks.rit.edu/theses/10529

Amer, T., Ngo, K. J., \& Hasher, L. (2017). Cultural differences in visual attention: Implications for distraction processing. British Journal of Psychology, 108(2), 244-258. Retrieved from https://doi.org/10.1111/bjop.12194

Bertelsen, A. S., Zeng, Y., Mielby, L. A., Sun, Y. X., Byrne, D. V., \& Kidmose, U. (2020). Crossmodal Effect of Vanilla Aroma on Sweetness of Different Sweeteners among Chinese and Danish Consumers. Food Quality and Preference, 87, 104036. Retrieved from https://doi.org/10.1016/j.foodqual.2020.104036

Boyle, G. J., Wongsri, N., Bahr, M., Macayan, J. V., \& Bentler, P. M. (2020). Cross-cultural differences in personality, motivation and cognition in Asian vs. Western societies. Personality and Individual Differences, 159, 109834. Retrieved from https://doi.org/10.1016/j.paid.2020.109834

Gajda, A., \& Oie, M. (2017). Between individualism and collectivism: Perception and profiles of creativity in Poland and Japan. Creativity. Theories-Research-Applications, 4(2), 198217. Retrieved from https://doi.org/10.1515/ctra-2017-0011

Gregory, S. E., Langton, S. R., Yoshikawa, S., \& Jackson, M. C. (2020). A cross-cultural investigation into the influence of eye gaze on working memory for happy and angry faces. Cognition and Emotion, 1-12. Retrieved from https://doi.org/10.1080/02699931.2020.1782353

Guess, C. D., Tuason, M. T., Göltenboth, N., \& Mironova, A. (2018). Creativity through the eyes of professional artists in Cuba, Germany, and Russia. Journal of Cross-Cultural Psychology, 49(2), 261-289. Retrieved from https://doi.org/10.1177/0022022117730817

Gutchess, A., \& Boduroglu, A. (2019). Cultural differences in categorical memory errors persist with age. Aging \& mental health, 23(7), 851-854. Retrieved from https://doi.org/10.1080/13607863.2017.1421616 
Jang, J. M., \& Shin, S. (2019). Content Order in Advertising and Thinking Styles: A CrossCultural Study of the United States and South Korea. Journal of Advertising, 48(5), 457472. Retrieved from https://doi.org/10.1080/00913367.2019.1663319

Jobson, L., Whittles, N., Tsecoutanis, E., Raj, S., Yew, R. Y., \& Haque, S. (2019). Investigating the mediating role of self-construal on the relationship between cultural group (Malay and Australian) and the characteristics and functional use of autobiographical memory. Memory, 27(8), 1054-1062. Retrieved from https://doi.org/10.1080/09658211.2019.1619776

Köster, M., Itakura, S., Yovsi, R., \& Kärtner, J. (2018). Visual attention in 5-year-olds from three different cultures. PloS one, 13(7), e0200239. Retrieved from https://doi.org/10.1371/journal.pone.0200239

Matsunaga, R., Yasuda, T., Johnson-Motoyama, M., Hartono, P., Yokosawa, K., \& Abe, J. I. (2018). A cross-cultural comparison of tonality perception in Japanese, Chinese, Vietnamese, Indonesian, and American listeners. Psychomusicology: Music, Mind, and Brain, 28(3), 178. Retrieved from https://doi.org/10.1037/pmu0000219

Steinmetz, M. K. R., Sturkie, C. M., Rochester, N. M., Liu, X., \& Gutchess, A. H. (2018). Crosscultural differences in item and background memory: examining the influence of emotional intensity and scene congruency. Memory, 26(6), 751-758. Retrieved from https://doi.org/10.1080/09658211.2017.1406119

Motevalli, S., Roslan, S. B., Sulaiman, T., Hamzah, S. G., Hassan, N. C., \& Garmjani, M. G. (2013). New study skills training intervention for students who suffer from test anxiety. Asian Social Science, 9(7), 85.

Nemeržitski, S. (2017). Implicit theories of creativity of secondary school students from Estonia and Russia: Effects of collectivism, Individualism, and a bilingual educational environment. Creativity Research Journal, 29(1), 56-62. Retrieved from https://doi.org/10.1080/10400419.2017.1263510

Ploom, K., Pentus, K., Kuusik, A., \& Varblane, U. (2020). The Effect of Culture on the Perception of Product Packaging: A Multimethod Cross-Cultural Study. Journal of International Consumer Marketing, 32(3), 163-177. Retrieved from https://doi.org/10.1080/08961530.2019.1660752

Sabiniewicz, A., Karwowski, M., Löckenhoff, C. E., Borkowska, B., \& Sorokowski, P. (2020). Short-and long-term memory and age in a traditional tribe (Dani of Papua) and a modern population (Poland). acta ethologica, 23(3), 135-142. Retrieved from https://doi.org/10.1007/s10211-020-00348-5

Saulton, A., Bülthoff, H. H., De La Rosa, S., \& Dodds, T. J. (2017). Cultural differences in room size perception. PloS one, 12(4), e0176115. Retrieved from https://doi.org/10.1371/journal.pone.0176115

Storme, M., Lubart, T., Myszkowski, N., Cheung, P. C., Tong, T., \& Lau, S. (2017). A CrossCultural Study of Task Specificity in Creativity. The Journal of Creative Behavior, 51(3), 263-274. Retrieved from https://doi.org/10.1002/jocb.123

Takao, S., Yamani, Y., \& Ariga, A. (2018). The gaze-cueing effect in the United States and Japan: Influence of cultural differences in cognitive strategies on control of attention. Frontiers in psychology, 8, 2343. Retrieved from https://doi.org/10.3389/fpsyg.2017.02343

Trachootham, D., Satoh-Kuriwada, S., Lam-ubol, A., Promkam, C., Chotechuang, N., Sasano, T., \& Shoji, N. (2018). Differences in taste perception and spicy preference: a Thai- 
INTERNATIONAL JOURNAL OF ACADEMIC RESEARCH IN PROGRESSIVE EDUCATION AND

DEVELOPMENT

Vol. 10, No. 3, 2021, E-ISSN: 2226-6348 @ 2021 HRMARS

Japanese cross-cultural study. Chemical senses, 43(1), 65-74. Retrieved from https://doi.org/10.1093/chemse/bjx071

Xie, G., \& Paik, Y. (2019). Cultural differences in creativity and innovation: are Asian employees truly less creative than western employees?. Asia Pacific Business Review, 25(1), 123-147. Retrieved from https://doi.org/10.1080/13602381.2018.1535380

Wiberg, J., \& Månsson, J. (2019). Consumers' perceptions of social media advertisements: a cross-cultural comparison among Sweden, India, and Japan. Retrieved from http://urn.kb.se/resolve?urn=urn:nbn:se:hkr:diva-20613 